\title{
Microglia in Infectious Diseases of the Central Nervous System
}

\author{
Monica M. Mariani and Tammy Kielian \\ Department of Pathology and Microbiology, University of Nebraska Medical Center, 985900 \\ Nebraska Medical Center, Omaha, NE 68198-5900, USA
}

\begin{abstract}
Microglia are the resident macrophage population in the central nervous system (CNS) parenchyma and, as such, are poised to provide a first line of defense against invading pathogens. Microglia are endowed with a vast repertoire of pattern recognition receptors that include such family members as Toll-like receptors and phagocytic receptors, which collectively function to sense and eliminate microbes invading the CNS parenchyma. In addition, microglial activation elicits a broad range of pro-inflammatory cytokines and chemokines that are involved in the recruitment and subsequent activation of peripheral immune cells infiltrating the infected CNS. Studies from several laboratories have demonstrated the ability of microglia to sense and respond to a wide variety of pathogens capable of colonizing the CNS including bacterial, viral, and fungal species. This review will highlight the role of microglia in microbial recognition and the resultant antipathogen response that ensues in an attempt to clear these infections. Implications as to whether microglial activation is uniformly beneficial to the CNS or in some circumstances may exacerbate pathology will also be discussed.
\end{abstract}

\section{Keywords}

microglia; bacterial meningitis; brain abscess; Lyme neuroborreliosis; Toxoplasma encephalitis; cerebral malaria; fungal infections; review

\section{Introduction}

Microglia are the resident macrophage population in the central nervous system (CNS) parenchyma and represent one arm of the innate immune response. Microglia are capable of recognizing a wide array of infectious pathogens that can colonize the CNS including bacteria, viruses, and fungi. They accomplish this task, in part, by their arsenal of pattern recognition receptors (PRRs) that sense highly conserved microbial motifs, termed pathogen-associated molecular patterns (PAMPs; Kielian 2006). Among the PRRs that are expressed by microglia include members of the Toll-like receptor (TLR) and scavenger receptor families. A detailed description of these receptor groups is not the objective of this review; therefore, the reader is referred to recent reviews of these topics for further information (Husemann et al. 2002; Kielian 2006; Larsen et al. 2007).

Since many infectious pathogens engage TLR signaling in microglia, a brief overview of this pathway will be introduced; however, the reader should consult several excellent reviews for more detailed information (Akira 2006; O'Neill and Bowie 2007). In general, TLR engagement elicits the production of inflammatory mediators from activated cells, whereas phagocytosis is not directly modulated by TLRs. However, TLR signaling can indirectly impact phagocytosis 
via the cytokines released by the former, culminating in altered expression levels of various phagocytic receptors (Mukhopadhyay et al. 2004; Underhill and Gantner 2004).

There are several major adaptor molecules utilized by members of the TLR family for transducing activation signals to various pathogen motifs (Akira 2006; O'Neill and Bowie 2007). The major adaptor molecule is MyD88, which is utilized by all of the TLRs identified to date with the exception of TLR3. MyD88 associates with the serine/threonine kinase interleukin-1 receptor-associated kinase, which interacts with the tumor necrosis factor (TNF) receptor-associated factor (TRAF) adaptor protein TRAF6, which provides a bridge to the protein kinase nuclear factor kappa B (NF-kB) inducing kinase (NIK). NIK then

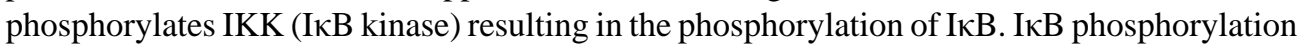
targets the protein for ubiquitination and proteasome-mediated degradation, resulting in the release and nuclear translocation of NF- $\mathrm{KB}$, whereupon it can influence the expression of numerous immune response genes. In addition, to NF- $\mathrm{kB}$, the mitogen-activated protein kinase (MAPK) pathway is another major signaling cascade activated via a MyD88-dependent mechanism.

In contrast, recent evidence has unveiled the existence of alternative adaptor molecules that transduce signals from TLRs via a MyD88-independent pathway (Akira 2006; O'Neill and Bowie 2007). These adaptors include TRIF and TRAM which are pivotal for the expression of interferon (IFN)-inducible genes following TLR4 activation by lipopolysaccharide (LPS). In addition, TLR3-mediated signaling, which is induced by double-stranded RNA typical of viral infections, utilizes the adaptor protein TRIF. Since the current review does not address the impact of viruses on microglial activation, this pathway will not be further discussed.

In response to pathogen stimulation, microglia can produce a wide array of pro-inflammatory mediators including reactive oxygen/nitrogen intermediates, cytokines, and chemokines (Aloisi 2001; Hanisch 2002; Tambuyzer et al. 2009). In general, similar secretion profiles are elicited from activated microglia, although tailored responses also exist with certain microbial stimuli (McKimmie et al. 2006). The net effect of microglial activation during CNS infection in vivo is to facilitate the recruitment and subsequent activation of infiltrating immune cell subsets. In this way, microglia can influence both the innate and adaptive arms of the immune response during CNS infection. In this review, we will discuss mechanisms utilized by microglia for pathogen recognition and highlight several infectious disease models where microglia have been suggested to impact the CNS response to infection. Due to space constraints, we have elected to focus on a few select infectious diseases and apologize to those authors whose work we were not able to cite in this venue.

\section{Microglial responses to bacteria that colonize the CNS}

\section{Pathogens associated with bacterial meningitis}

Streptococcus pneumoniae is of clinical significance because it represents the most frequent cause of bacterial meningitis (Koedel et al. 2002; Nau and Bruck 2002). There are currently 1.2 million cases of bacterial meningitis worldwide resulting in approximately 135,000 deaths annually (Galiza and Heath 2009; Somand and Meurer 2009). Effects from meningitis can range from hearing loss, hydrocephalus, memory deficits, cerebral palsy, and seizures (Koedel et al. 2002; Nau and Bruck 2002). The establishment of bacterial meningitis requires a sequence of events including nasopharynx colonization, invasion, and replication in the bloodstream, penetration of the blood-brain barrier (BBB), and survival and replication in the subarachnoid space. S. pneumoniae-induced meningitis results in a mortality rate in adults of approximately $30 \%$, with neurologic sequelae in 30\% to 50\% of those survivors (Garcao et al. 2006; Nau and Bruck 2002; Pfister et al. 1993). 
The contribution of microglia to defense against pneumococcal species is similar to that for other infectious agents, i.e., in the initial immune response and recruitment of leukocytes from the peripheral circulation to the site of infection (Rock et al. 2004). However, studies have also revealed that microglia can contribute to neuronal damage during pneumococcal meningitis (Nau and Bruck 2002). This information has primarily been revealed using rodent experimental meningitis models. For example, Djukic et al. showed in a murine model of infection that approximately $24 \mathrm{~h}$ after $S$. pneumoniae exposure, green fluorescent protein-expressing microglia/macrophages underwent a morphological transformation to an activated phenotype and upregulated major histocompatibility complex (MHC) class II molecules (Djukic et al. 2006). In addition, inflammatory processes triggered by parenchymal glia have been implicated in contributing to cerebral edema, which is a major cause of death and neurological sequelae in S. pneumoniae meningitis (Koedel et al. 2002; Nau and Bruck 2002; Scheld et al. 2002).

Since pneumococci can cross the BBB, microglia may respond directly to intact bacteria or to pneumococcal cell wall antigens. Indeed, microglia exposed to pneumococcal cell walls produced a wide array of inflammatory mediators including TNF- $\alpha$, interleukin (IL)- 6 , IL-12, keratinocyte-derived chemokine (CXCL1/KC), CCL2/MCP-1, CCL3/MIP-1 $\beta$, CXCL2/ MIP-2, and CCL5/RANTES, as well as soluble TNF receptor II, a TNF- $\alpha$ antagonist (Hanisch et al. 2001; Prinz et al. 1999; Rock et al. 2004). The production of these inflammatory mediators involved activation of the extracellular signal-regulated protein kinases ERK-1 and ERK-2 via a MAPK intracellular signaling pathway (Hanisch et al. 2001; Rock et al. 2004). This microglial-derived cytokine profile is effective at eliciting leukocyte recruitment into the CNS for the purpose of antibacterial defenses, but at the same time can also contribute to inflammatory mediator-induced neuronal damage representing a double-edged sword. Indeed, in an in vitro coculture model, neuronal damage was shown to result, at least partially, from NO production by activated microglia and astrocytes, which was greatly attenuated by dexamethasone (Kim and Tauber 1996). Another study has shown that the co-administration of fibronectin, an extracellular matrix protein elevated in the cerebrospinal fluid (CSF) of patients suffering from bacterial meningitis, with TLR agonists led to an additive effect on NO and TNF- $\alpha$ production by microglia compared to either stimulus alone (Goos et al. 2007). This finding suggests that the inflammatory response to pneumococci during bacterial meningitis may be exacerbated by endogenous molecules and could contribute to the pathological damage of neurons typical of infection.

Although neuronal damage and apoptosis is triggered, in part, by the inflammatory process via caspase activation, pneumococci can also directly induce cell death. Studies have demonstrated that unique pneumococcal factors can induce apoptosis in a variety of CNS cell types including primary rat hippocampal and cortical neurons as well as human microglia (Braun et al. 2001, 2002). Additional studies have identified several pathogenic factors of $S$. pneumoniae that are involved in mediating apoptosis including exotoxins, hydrogen peroxide $\left(\mathrm{H}_{2} \mathrm{O}_{2}\right)$, and the poreforming molecule pneumolysin, which induces cell death via translocation of intracellular calcium, and apoptosis-inducing factor (Braun et al. 2001, 2002). Either pneumolysin or $\mathrm{H}_{2} \mathrm{O}_{2}$ is sufficient to trigger mitochondrial damage and apoptosis in vitro, and inactivation of these toxic mediators effectively prevents this damage. Therefore, microglia not only are capable of sensing $S$. pneumoniae infection but are also a target of bacterial killing. The latter may represent a survival strategy to ensure bacterial persistence/replication. The net balance of these opposing mechanisms may contribute to the outcome of bacterial meningitis.

In addition to the secretion of pro-inflammatory mediators to elicit the recruitment of professional phagocytes including neutrophils and macrophages, microglia are also capable of exerting antimicrobial activity. For example, the expression and bactericidal properties of rat cathelin-related antimicrobial peptide, a homolog of the human cathelicidin peptide LL-37 which is present in CSF of patients with meningitis, had been demonstrated in microglia (Brandenburg et al. 2008). In addition, the expression of rat cathelin-related antimicrobial 
peptide in glial cells was induced by the inflammatory cytokines IL- $1 \beta$ and TNF- $\alpha$. In an infant rat model of experimental meningitis where $S$. pneumoniae was injected intracisternally, cathelin-related antimicrobial peptide was found to be localized in glia (Brandenburg et al. 2008). Collectively, these results suggest that cathelicidins produced by microglia and other CNS cell types likely play an important role in the innate immune response against CNS pneumococcal pathogens. It remains to be determined whether microglia express antimicrobial peptides in response to other CNS infections; however, this appears likely based on the pivotal role of antimicrobial peptides in neutralizing bacteria in other professional phagocytes such as neutrophils and macrophages. Other studies have focused on microglial interactions with bacterial surface proteins. Peppoloni et al. have shown that the lack of a pneumococcal surface protein $\mathrm{C}$ (PspC), which is expressed in $75 \%$ of pneumococcal strains, significantly enhances the susceptibility of $S$. pneumoniae to both bactericidal activity and secretory responses from microglial cells, suggesting that this molecule may play an important role in CNS immune invasion by pneumococci (Peppoloni et al. 2006). In addition, electron microscopy studies revealed that micro-glia interacted more efficiently with PspC mutant than with PspC wildtype (WT) pneumococci and produced significantly higher levels of TNF- $\alpha$, MIP-2, IL-10, and nitric oxide in response to the former (Peppoloni et al. 2006). Collectively, these findings suggest that PspC could be a potential target for developing a protein-based vaccine against pneumococcal meningitis. This is an attractive possibility based on the fact that approximately $75 \%$ of all pneumococcal species express PspC, which would ensure broad efficacy for multiple strains of the organism.

In contrast to S. pneumoniae, group B streptococcal species (GBS) present more of a threat to neonates than adults. GBS is responsible for $50 \%$ of all cases of neonatal meningitis and is the third most frequent cause of bacterial meningitis overall (Lehnardt et al. 2007; Manning 2003). GBS accounts for such a large percentage of neonatal meningitis because they are among the first bacterial species that the fetus encounters due to colonization of the birth canal in up to $30 \%$ of pregnant women (Manning 2003; Wennekamp and Henneke 2008). Similar to meningitis caused by $S$. pneumoniae, GBS-induced neonatal meningitis results in symptoms such as long-term neurological deficits, language disorders, seizures, and motor handicaps in surviving infants (Manning 2003). Lehnardt et al. previously demonstrated that the interaction of TLR2 with GBS leads to microglial activation and NO production (Lehnardt et al. 2007). A similar theme between the balance of beneficial versus detrimental microglial responses can be envisioned in terms of NO production. For example, NO represents a potent bactericidal mechanism but, concomitantly, can elicit neuron cell death when produced at high levels or for a chronic duration. Lehnardt et al. further reported that GBS not only activates microglia but also induces apoptosis in these cells via TLR2 and its adaptor molecule MyD88 independent of toxic mediators, such as NO (Lehnardt et al. 2007). Interaction of GBS with TLR2 resulted in the activation of caspase-8, but not the classical apoptosis effector caspase-3, a process that involved the transcription factor family Ets. The authors suggested that TLR2- and caspase-8mediated microglial apoptosis constitutes an autoregulatory mechanism that serves to limit GBS-induced overactivation of the CNS innate immune response (Lehnardt et al. 2007).

\section{Microglial responses to pathogens associated with brain abscesses}

Brain abscesses are serious CNS sequelae that form in response to parenchymal colonization by pyogenic bacteria and account for one in every 10,000 hospital admissions in the USA of an infectious disease nature (Kielian 2004; Lu et al. 2006; Townsend and Scheld 1998). The ensuing formation of an abscess at the site of infection may result in edema, inflammation, neuronal toxicity, seizures, and long-term cognitive loss (Kielian et al. 2004). Brain abscesses can arise from proximate or distal infections such as the middle ear, sinuses, teeth, or penetrating trauma to the skull, although colonization of the brain by bacteria originating from a systemic site of infection is most common (Mathisen and Johnson 1997; Townsend and 
Scheld 1998). An important distinction between bacterial meningitis and brain abscess lies in the distinct anatomical localization of infection. For example, the infection of brain parenchyma during abscess development gives microglia immediate access to the inciting pathogen compared to bacterial meningitis where microglia encounter the pathogen later because of its initial sequestration in the subarachnoid space. Importantly, unique profiles of immune activation have been observed in both models, which might extend beyond the use of divergent bacterial species (Kielian 2004). Pyogenic bacteria initiate parenchymal infections and generate a localized area of cerebritis which develops into a purulent abscess surrounded by a well-vascularized fibrotic capsule (Kielian 2004). Brain abscesses are also characterized by extensive edema and tissue necrosis and have a propensity to localize at white-gray matter junctions where the microcirculatory flow is poor (Townsend and Scheld 1998). The most common etiologic agents of brain abscesses in humans are streptococcal species and Staphylococcus aureus (Jones et al. 2004; Prasad et al. 2006). In addition to the sequential progression from cerebritis to necrosis during brain abscess evolution, the activation of resident glial cells is a hallmark of infection (Kielian 2004). Specifically, microglial and astrocyte activation is evident immediately following the entry of bacteria into the CNS parenchyma and persists throughout abscess development (Baldwin and Kielian 2004). A murine model of experimental brain abscess developed in our laboratory has demonstrated that S. aureusinduced brain abscesses elicit the rapid and sustained expression of numerous proinflammatory cytokines and chemokines including IL-1 $\beta$, TNF- $\alpha$, IL-12 p40, CXCL2/MIP-2, CCL2/MCP-1, CCL3/MIP-1 $\alpha$, and CCL4/MIP-1 $\beta$ (Kielian et al. 2001, 2004, 2007). As the resident innate immune effector cells of the brain parenchyma, microglia elicit leukocyte recruitment into the infected CNS to facilitate bacterial clearance during abscess development. Our laboratory has demonstrated that microglia exert $S$. aureus bactericidal activity and that the organism is a potent inducer of numerous inflammatory molecules in microglia including but not limited to TNF- $\alpha$, IL-1 $\beta$, and CXCL1 (Esen and Kielian 2006; Gurley et al. 2008; Kielian et al. 2005, 2002). However, it is important to note that, in our experience, the degree of $S$. aureus phagocytosis and killing by microglia is significantly less potent compared to professional phagocytes (i.e., PMN and macrophages). Our group also reported that intact $S$. aureus and its cell wall product peptidoglycan (PGN) enhanced TLR1, TLR2, TLR6, and CD14 expression in murine microglia, which may serve to augment microglial activation during CNS infection (Kielian et al. 2002). Another link to TLR2 and brain abscess pathogenesis was recently revealed where abscesses of TLR2 KO mice where shown to have a significant increase in the frequency of IL-17-producing Th17 cells, suggesting the presence of an alternative pathway available to respond to $S$. aureus infection that may involve Th17 cells (Nichols et al. 2009). Microglia, astrocytes, and macrophages were shown to express both receptors for IL-17, namely IL-17RA and IL-17RC, indicating that these cells may be primed to respond to IL-17 during brain abscess development (Nichols et al. 2009). However, despite receptor expression, IL-17 was relatively ineffective at eliciting microglial activation in terms of cytokine/chemokine induction. In contrast, IL-17 potentiated CXCL2 and CCL2 expression when combined with TNF- $\alpha$ in macrophages but not microglia (Nichols et al. 2009). This suggests that IL-17R expression does not directly equate with cytokine responsiveness and the mechanism(s) responsible for the relative inability of microglia to respond to IL-17 is unknown. Since IL-17 has been proposed to signal through a heterodimeric receptor composed of IL-17RA and IL-17RC (Toy et al. 2006), it is possible that there are differences in receptor combinations between microglia and macrophages (Ishigame et al. 2009). Alternatively, signaling and/or adaptor proteins downstream of IL-17Rs may be differentially expressed within these cell types. However, we cannot discount a role for IL-17 in regulating other functions of microglia that were not examined in our recent study including phagocytosis, chemotaxis, and/or increased responsiveness to other inflammatory signals. Another possibility is that microglia may respond poorly to IL-17 and longer incubation periods with the cytokine are required to detect cell activation. Since our recent studies examined the ability of IL-17 to elicit microglial pro-inflammatory mediator release $24 \mathrm{~h}$ following cytokine 
treatment, it is possible that some effects may have been detected at a later interval (i.e., $48 \mathrm{~h}$ ). A few recent studies by other laboratories have reported that IL-17 is capable of inducing microglial activation as measured by the production of select pro-inflammatory mediators (Das Sarma et al. 2009; Kawanokuchi et al. 2008; Trajkovic et al. 2001); however, the expression of these factors was rather low, and as such, the biological impact of IL-17 on microglial activation remains an open question.

Common to the numerous TLRs that participate in immune responses to bacteria is the central adaptor molecule, MyD88, which transduces activation signals emanating from all TLRs with the exception of TLR3 (Akira 2006; O'Neill and Bowie 2007). MyD88-dependent signaling leads to the induction of pro-inflammatory mediator expression and immune effector functions. Previous work from our laboratory has demonstrated a pivotal role for MyD88-dependent pathways in the recognition of both intact $S$. aureus and PGN as revealed by the relative paucity of pro-inflammatory molecule release in primary microglia isolated from MyD88 knockout (KO) mice (Esen and Kielian 2006). Interestingly, this phenotype differs from what was observed with TLR2 KO microglia, where the receptor was implicated in microglial activation in response to PGN but not intact bacteria suggesting that the latter is recognized by a cadre of alternative receptor(s) (Kielian et al. 2005). However, the assumption that the nonresponsiveness to $S$. aureus demonstrated by MyD88 KO microglia is exclusively attributable to the actions of multiple TLRs cannot be drawn since this adaptor also transduces signals emanating from the IL-1R and IL-18R (Adachi et al. 1998; Burns et al. 1998; Wesche et al. 1997), and our laboratory has shown that IL-1 is important for the genesis of an effective CNS immune response to $S$. aureus in vivo (Kielian et al. 2004). Based on the complexity of intact bacteria harboring an arsenal of diverse PAMPs, it is highly likely that $S$. aureus recognition by microglia is mediated by numerous PRRs in a cooperative fashion. We have also recently examined the importance of MyD88-dependent signals during brain abscess formation and found that this adaptor is essential for the genesis of an effective antibacterial response (Kielian et al. 2007). Specifically, MyD88 KO mice succumbed to infection within $48 \mathrm{~h}$ following bacterial exposure, which coincided with significantly reduced expression of several pro-inflammatory mediators, including but not limited to IL- $1 \beta$, TNF- $\alpha$, and MIP-2/ CXCL2 (Kielian et al. 2007). These changes were associated with a significant reduction in neutrophil and macrophage recruitment into brain abscesses of MyD88 KO animals, as well as a reduction in TNF- $\alpha$, IL-6, MIP-1 $\alpha /$ CCL3, and IFN- $\gamma$-induced protein 10/CXCL10 expression from isolated microglia associated with brain abscesses of MyD88 KO animals (Kielian et al. 2007).

Although studies in MyD88 KO mice suggested that microglia may play a pivotal role in the initial bacterial recognition event by virtue of the rapid innate immune defects observed, this question could not be addressed in our earlier study since MyD88 expression was globally absent in KO animals (Kielian et al. 2007). To address this question, we engineered radiation bone marrow chimera mice where MyD88 was differentially expressed in the CNS versus peripheral immune cell compartments (Garg et al. 2009). Unexpectedly, the results demonstrated that MyD88 expression in the CNS was required to mount an innate immune response equivalent to wild type during the acute stage of brain abscess development. The requirement for MyD88 in CNS resident cells was reinforced by the finding that neutrophil influx into the infected brain was only achieved in chimeric mice where MyD88 was present in the CNS. This is likely due to the fact that numerous neutrophil chemokines were restored to WT levels only in animals where MyD88 was expressed in the CNS compartment (Garg et al. 2009). These findings strongly implicate CNS intrinsic cells as responsible for initiating a protective antibacterial response to $S$. aureus during the early stage of parenchymal infection. Whether MyD88 expression in microglia, astrocytes, or possibly other CNS cell type(s) is responsible for CNS immunity to $S$. aureus is not certain at present since a cell-specific ablation approach was not used in this study. Nonetheless, it is evident that microglia play an important 
role in sensing S. aureus in the CNS parenchyma and trigger a pro-inflammatory cascade that is essential for subsequent leukocyte recruitment and bacterial neutralization.

\section{Microglial recognition of Borrelia burgdorferi and Lyme neuroborreliosis}

The spirochete $B$. burgdorferi (sensu lato) is the etiologic agent of Lyme disease, the most frequently occurring vector-borne infection in the USA (Hengge et al. 2003; Rupprecht et al. 2008). B. burgdorferi transmission occurs through Ixodes ticks and is also endemic in Europe and parts of Asia. Lyme disease initially propagates in the skin before it disseminates through the blood stream to other organ systems. In addition, B. burgdorferi displays tissue tropism for the nervous system, where neurologic involvement occurs in up to $20 \%$ of patients who present with cranial neuritis, meningoradiculitis, or encephalitis (Pfister et al. 1994; Rupprecht et al. 2008). Colonization of the CNS with $B$. burgdorferi from the blood is associated with inflammation of the meninges, nerve roots, brain, and spinal cord resulting in the clinical manifestations of neuroborreliosis (Pfister and Rupprecht 2006; Rupprecht et al. 2008). Furthermore, marked levels of pro-inflammatory molecules such as IL-6 and TNF- $\alpha$ are associated with Lyme disease, as well as the induction of an important inflammatory enzyme, cyclooxygenase-2 (COX-2; Ramesh et al. 2008; Rasley et al. 2002). However, the inflammatory mechanisms that are involved in the CNS immune responses to B. burgdorferi are not currently well understood based on the limited availability of an adequate animal model. To date, the only animal model where evidence of Lyme neuroborreliosis has been demonstrated is in rhesus macaques (Pachner et al. 2001).

Currently, most studies of Lyme disease utilize murine models. However, one major disadvantage of mouse models of infection is the failure of $B$. burgdorferi to colonize the CNS during a peripheral infection. To circumvent this barrier to CNS entry, bacteria have been injected intracerebrally; however, this approach raises issues regarding accurate modeling of BBB penetration by the organism. In vitro, B. burgdorferi has been shown to elicit the rapid production of pro-inflammatory cytokines from primary murine microglia (Rasley et al. 2006). Additionally, histological evidence obtained from patients with Lyme neuroborreliosis has demonstrated the presence of abundant reactive microglia/macrophages in the cerebral cortex immunostained with monoclonal antibodies for human leukocyte antigen group D related (HLA-DR) and CD68 (Miklossy et al. 2008). The distinction between microglia and macrophages cannot be made using immunohistochemical approaches since no unique marker has been identified to discriminate between these two cell types and the fact that infiltrating macrophages are a component of the inflamed CNS during Lyme neuroborreliosis. Currently, the only accepted method to distinguish microglia from infiltrating macrophages is by fluorescent-activated cell sorting based on their differential expression levels of the leukocyte common antigen CD45 (Carson et al. 1998; Ford et al. 1995; Sedgwick et al. 1991). However, the possibility of a microglial activation continuum has been proposed, where microglial CD45 expression may increase and possibly overlap with infiltrating macrophages and perivascular macrophages. Despite this possibility, differentiation of microglia from macrophages based on CD45 expression remains the accepted method; however, these caveats should be kept in mind. The accumulation of immunocompetent HLA-DR-positive microglia and reactive astrocytes in the cerebral cortex supports the involvement of glia during infection (Miklossy et al. 2008). However, it remains to be determined whether microglial/macrophage activation is a primary response to $B$. burgdorferi or rather a secondary phenomenon resulting from the inflammatory milieu created during infection. Moreover, microglial cells also responded to $B$. burgdorferi stimulation in vitro with a robust increase in HLA-DR, HLA-DQ, and the dendritic cell (DC) marker CD11c (Cassiani-Ingoni et al. 2006). Several studies suggest that granulocyte macrophage colony-stimulating factor (GM-CSF) is capable of transitioning microglia toward a dendritic cell phenotype (Fischer and Reichmann 2001; Mausberg et al. 2009; Ponomarev et al. 2005); however, these effects are likely dose dependent (Esen and Kielian 2007). From a 
functional perspective, it is intriguing to speculate that during CNS infections where local concentrations of GM-CSF may be sufficient to drive microglia to a DC-like phenotype, this could have important ramifications on antigen presentation in the infected CNS based on the well-known potency of DCs as antigen-presenting cells. It has also been shown that exposure of microglia to B. burgdorferi lysate in vitro increases expression of TLR1, TLR2, TLR4, and TLR5 (Bernardino et al. 2008; Cassiani-Ingoni et al. 2006). In contrast to the murine Lyme disease model, a primate model involving the rhesus macaque displays relatively subdued or absent upregulation of TLR transcripts in response to TLR ligands or B. burgdorferi and is perhaps the consequence of differences between these animal species or in the dose of stimulants used (Bernardino et al. 2008). The pro-inflammatory molecules elicited by TLR activation could be a significant factor in the pathogenesis of Lyme neuroborreliosis. Recently, studies have utilized primary microglia or cortical tissue recovered from primate brains to examine microglial interactions with B. burgdorferi (Bernardino et al. 2008, 2009; Ramesh et al. 2008). Since the organism is able to gain entry into the primate CNS from a peripheral infection, the use of primate microglia is highly relevant to the natural homing of the bacterium. Interestingly, CXCL12 expression was significantly increased in B. burgdorferi-stimulated microglia in vitro, and elevated CXCL12 levels have been detected in vivo in the cerebrospinal fluid of patients with Lyme neuroborreliosis (Pashenkov et al. 2002). Furthermore, CXCL12 is known to direct dendritic cells as well as neural/glial progenitor cells to sites of injury in the CNS, which can stimulate tissue repair.

In an innovative method to investigate the contribution of glia to pro-inflammatory mediator release in response to $B$. burgdorferi, Ramesh et al. utilized frontal cortex tissue explants from rhesus macaques exposed to live spirochetes (Ramesh et al. 2008). This approach is more accurate at being able to assign mediator production to microglia, since any potential contribution from infiltrating monocytes/macrophages are minimal since blood flow is no longer a factor. These studies demonstrated that microglia expressed IL-1 $\beta$, IL-8, CXCL13, and COX-2 upon exposure of cortical explants to B. burgdorferi (Ramesh et al. 2008). The authors also noted apoptotic death of neurons and oligodendrocytes following spirochete treatment, suggesting that in addition to direct damage by the bacteria, the glial response to $B$. burgdorferi likely also contributes to cell death.

B. burgdorferi has also been shown to induce the late production of significant quantities of the anti-inflammatory cytokine IL-10 by both microglia and astrocytes (Rasley et al. 2006). The delayed production of IL-10 suggests the possibility that a negative feedback loops exist whereby bacteria within the CNS elicit IL-10 expression by microglia and astrocytes limiting potentially damaging inflammation within the brain parenchyma during persistent infections (Rasley et al. 2006). Evidence to support this possibility was found in a recent study where treatment of primary rhesus macaque microglia with the tetracycline analogs doxycycline and minocycline attenuated microglial pro-inflammatory mediator responses to $B$. burgdorferi (Bernardino et al. 2009). Tetracyclines, doxycycline in particular, are used for the treatment of chronic Lyme disease patients and have been shown to improve adverse clinical symptoms at a point where viable spirochetes cannot be easily detected. Together, these evidences suggest that inappropriate immune activation may be playing a role during chronic disease. Therefore, the dampening of microglial pro-inflammatory cascades to favor anti-inflammatory pathways following pathogen eradication may benefit patient outcome from Lyme neuroborreliosis, although this conjecture remains speculative at the present time.

\section{Parasitic infections and recognition by microglia Toxoplasma gondii}

Toxoplasma encephalitis (TE) is the most common opportunistic infection of the CNS in patients with acquired immune deficiency syndrome (AIDS) and other immunocompromised 
individuals (Kim and Weiss 2008; Montoya and Liesenfeld 2004). In these patients, TE most likely results from reactivation of latent Toxoplasma cysts in the brain, where they persist after primary infection as tachyzoites. The specific mechanisms of TE reactivation have only been partially defined. The decline of $\mathrm{CD}^{+} \mathrm{T}$ lymphocytes and the functional disturbance of these cells are of key importance in reactivation, and impairments in $\mathrm{CD}^{+} \mathrm{T}$ cells, macrophages, and natural killer (NK) cells as well as IFN- $\gamma$ production may also contribute to insufficient immunological control of the parasite (Murray et al. 1984; Schluter et al. 1995). In addition, dysregulation of microglial activation, which occurs in the CNS of HIV-infected individuals, could participate in reactivation of TE since this represents an opportunistic infection (Schluter et al. 1995). T. gondii uses many methods to evade CNS host defenses, including the ability to downregulate activation-induced MHC class II expression in microglia (Luder et al. 2003). The current knowledge of immune responses to $T$. gondii is largely based on experimental studies in rodents. However, various studies suggest that experimental toxoplasmosis in the rat may represent a better system because this model more closely parallels the course of infection in humans (Schluter et al. 1995).

Initially, $\mathrm{CD}^{+}{ }^{+}$and $\mathrm{CD}^{+} \mathrm{T}$ cells and NK cells work in concert with resident CNS cell populations such as microglia to suppress the proliferation of $T$. gondii tachyzoites in the CNS, primarily through the actions of IFN- $\gamma$ (Rock et al. 2004). Murine microglia, as well as astrocytes, neurons, and oligodendrocytes, are susceptible to infection with tachyzoites (Fischer et al. 1997). In the rat model, intracerebral replication of $T$. gondii occurs primarily within neurons and astrocytes, as activated microglia appear to effectively inhibit growth, indicating that microglia may be the major effector cells in the prevention of $T$. gondii tachyzoite proliferation in the CNS (Luder et al. 1999). In further support of this theory, previous studies by Chao et al. have shown that both murine and human microglia inhibit tachyzoite proliferation following treatment with IFN- $\gamma$ and LPS (Chao et al. 1993, 1994). The inhibitory effects of activated microglia are due, in part, to NO-mediated effects on intracellular replication of tachyzoites. This was demonstrated by Chao et al. where murine microglia stimulated with IFN- $\gamma+$ LPS in the presence of the NO inhibitor NG-monomethyl-L-arginine, abrogated their antitoxoplasmic activity (Chao et al. 1993, 1994). Furthermore, IFN- $\gamma+$ TNF$\alpha$ inhibits $T$. gondii multiplication in a dose-dependent manner in murine microglia and TGF$\beta$ suppresses this antitoxoplasmic activity by interfering with $\mathrm{NO}$ generation (Chao et al. 1993; Peterson et al. 1994). Freund et al. also reported that IFN- $\gamma+$ TNF- $\alpha$-treated microglia inhibited $T$. gondii replication via both NO-and IFN- $\gamma$-dependent mechanisms and independent of reactive oxygen intermediate generation or tryptophan degradation (Freund et al. 2001). Studies have also shown that mice lacking TNF- $\alpha$ or lymphotoxin- $\alpha$ had reduced inducible nitric oxide synthase (iNOS) expression and succumbed readily to intracranial toxoplasmosis, thus implicating the vital role of these cytokines during infection (Schluter et al. 2003). Interestingly, microglia also inhibited tachyzoite replication when exposed to GM-CSF, but not M-CSF, via the generation of NO (Fischer et al. 1993). Another study has demonstrated the importance of CD200-CD200R crosstalk on regulating microglial reactivity during TE (Deckert et al. 2006). Specifically, infection of CD200 KO mice with $T$. gondii led to enhanced microglial proliferation and heightened TNF- $\alpha$ and iNOS expression. These changes coincided with a reduction in intracerebral parasite levels and mortality rates (Deckert et al. 2006). These findings suggest that more robust microglial activation may be beneficial for parasite clearance from the CNS; however, a tight regulatory mechanism must be present to prevent this response from becoming pathological and exerting unwanted damage to surrounding noninfected parenchyma.

It is important to note here discrepancies between the findings obtained with rodent versus human microglia in response to T. gondii. Specifically, in contrast to the observations with murine microglia, Chao et al. reported that host defense activity of human microglia against T. gondii is mainly reliant on the immune-activating properties of IFN- $\gamma$, TNF- $\alpha$, and IL-6, 
which reduced $T$. gondii entry into microglia, and was not due to the antitoxoplasmic activity of NO as was observed in murine microglia (Chao et al. 1994). The reason for this discrepancy is not clear; however, it is well recognized that iNOS expression and subsequent NO production is typically more prominent in rodent macrophages and microglia compared to human cells (Colton et al. 1996; Kleinert et al. 2004; Schneemann et al. 1993). Unfortunately, once tachyzoites gain entry into human microglia, cytokine treatment has little or no effect on replication (Chao et al. 1994).

Despite widespread CNS activation due to T. gondii, murine microglia and astrocytes are the main resident innate immune cells that produce chemokines which actively recruit inflammatory leukocytes from the periphery (Rock et al. 2004). Parenchymal microglia have been shown to produce CCL5/RANTES, CXCL9/MIG, and CXCL10/IP-10 during acute TE (Schluter et al. 1997; Strack et al. 2002). In addition, Deckert-Schluter et al. performed IL-10 neutralization experiments in vivo revealing that this anti-inflammatory cytokine facilitates $T$. gondii persistence in the brain by suppressing the CNS immune response (Deckert-Schluter et al. 1997). However, it is important to acknowledge that IL-10 has a dual function whereby microglial production of IL-10 can reduce host tissue inflammation resulting in less neuronal damage during the host immune response (Rozenfeld et al. 2003). Therefore, regulation of IL-10 levels during TE likely plays an important role in dictating whether parasite neutralization or persistence occurs. Collectively, microglia may function to fine-tune chemotaxis throughout the course of $T$. gondii infection by directing inflammatory leukocytes to the location of parasites within the CNS concomitant with reducing neuronal damage and suppressing the immune response. The sum of such actions likely dictates $T$. gondii survival/ persistence in the infected CNS.

\section{Plasmodium falciparum}

When $P$. falciparum crosses the BBB, the parasite can induce cerebral malaria (CM), a serious neurological disease that results in approximately two million deaths annually (Hunt et al. 2006). Pathological features of CM include infected erythrocyte-filled cerebral venules, microhemorrhages, ischemia, rampant glial proliferation, and the formation of microglial and astrocyte aggregates referred to as Durck's granulomas (Deininger et al. 2002; Idro et al. 2005). A prominent feature of human CM is widespread activation of microglial cells (Deininger et al. 2002; Schluesener et al. 1998). Murine models of CM also exhibit microglial activation typified by TNF- $\alpha$ production, which may be important in the initiation and perpetuation of the cerebral complications associated with this disease (Medana et al. 2000, 1997; Schofield and Grau 2005). Additionally, examination of the cerebrospinal fluid of Kenyan children with CM demonstrated increased levels of excitotoxins, which are products of microglia and infiltrating macrophages (Dobbie et al. 2000). An important role for matrix metalloproteinases in the pathogenesis of $\mathrm{CM}$ has been suggested, where enzyme expression by numerous CNS cell types, including microglia, has been implicated in blood-brain barrier damage and neuron survival (Szklarczyk et al. 2007).

Recent investigations have implicated microglia in the pathogenesis of CM (Rock et al. 2004). The most widely utilized murine model of CM is a "fatal" model involving CBA/T6 mice infected with Plasmodium berghei ANKA (CBA-PbA; Engwerda et al. 2005). This fatal murine cerebral malaria (FMCM) model exhibits neurological and histological alterations analogous to those observed in human CM (Engwerda et al. 2005). In this model, changes in microglia occur within 2 to 3 days postinoculation, which predates the onset of cerebral symptoms by at least 3 days (Medana et al. 1997). To establish the extent to which inflammation exacerbates CM, mice were treated with dexamethasone, which is capable of inhibiting TNF$\alpha$ production by LPS-stimulated murine and human microglia in vitro (Medana et al. 2000). TNF- $\alpha$ plays an essential role in the pathogenesis of FMCM, and microglia produce this 
cytokine during the course of the disease (Rock et al. 2004). The earlier the infected mice were treated with dexamethasone, less microglial activation was observed, which directly correlated with less severe neurological symptoms (Medana et al. 2000). Microglial activation and neurological symptoms were completely abrogated in mice treated with dexamethasone at the time of parasite inoculation, and importantly, dexamethasone treatment did not inhibit the growth of the parasite (Medana et al. 2000). These results suggest that parasite antigens and soluble factors released into the circulation following parasite replication, in the absence of an immune response, are insufficient to activate microglia.

The role that TLRs and their adaptor molecules play during CM pathogenesis remain controversial. Mice deficient in MyD88, but not in TRIF, displayed significantly less CM characteristic neurological symptoms, which resulted in significantly reduced mortality, thus implicating TLR signaling pathway(s) in cytokine-induced damage (Coban et al. 2007). A similar role for MyD88-dependent signals during CM was reported by another group (Griffith et al. 2007); however, the host genetic background was found to influence CM pathogenesis. In contrast, two separate laboratories reported that activation of the host innate immune response and CM development is not dependent on the engagement of TLR2, TLR4, or TLR9 (Lepenies et al. 2008; Togbe et al. 2007). The reason(s) responsible for these conflicting reports is not clear but may originate from the functional redundancy of TLR signals and/or differences in the length of experimental CM infection. The relative importance of TLRs in facilitating microglial recognition of $P$. berghei ANKA and the subsequent release of inflammatory mediators remain to be examined.

During the course of malarial infection, phagocytic cells play a key role in the uptake of parasitized erythrocytes (PE). The recognition and phagocytosis of $P$. falciparum $\mathrm{PE}$ by macrophages has been shown to be mediated predominantly by the scavenger receptor CD36 (McGilvray et al. 2000; Patel et al. 2004). Although microglia express CD36 (Husemann et al. 2002), to our knowledge, no studies have been published to date regarding the potential of CD36 to influence microglial responses to $P$. falciparum or the pathogenesis of CM.

\section{Microglial responses to CNS fungal pathogens Cryptococcus neoformans}

C. neoformans is an opportunistic encapsulated yeast that is an etiologic agent of cryptococcal meningoencephalitis and meningitis as well as the most frequent and severe AIDS-related fungal infection (Rock et al. 2004; Zhou et al. 2007). C. neoformans initially infects the respiratory tract and subsequently disseminates throughout the CNS (Shimoda et al. 2006). Importantly, MHC class II-positive perivascular microglia have been identified as a critical player in host resistance to C. neoformans (Zhou et al. 2007; Aguirre and Miller 2002).

Resistance to C. neoformans is not limited to innate immunity since adaptive immunity is also required to effectively combat fungal infections (Aguirre and Miller 2002; Hill and Aguirre 1994). Antifungal defense is mainly dependent on $\mathrm{CD} 4^{+} \mathrm{T}$ cells and their cooperation with macrophages and microglia (Hill and Aguirre 1994). T cells have been shown to augment the antifungal activity of parenchymal microglia by secreting inflammatory cytokines such as IFN$\gamma$ (Rock et al. 2004). The addition of IFN- $\gamma$ to murine microglia in vitro has been shown to enhance phagocytosis and killing of C. neoformans (Blasi et al. 1995). Interestingly, opsonization is required for human microglia to ingest cryptococci whereas murine and porcine microglia can phagocytize cryptococci independently of opsonization (Blasi et al. 1995; Lee et al. 1995; Lipovsky et al. 1997). In contrast to murine microglia, human microglia are not capable of killing cryptococci probably due to insufficient production of $\mathrm{NO}$ as compared to the high levels of NO production by murine microglia (Chao et al. 1994; Peterson et al. 1994). However, C. neoformans was shown to induce chemokine secretion from human primary cultures of microglia in the presence of anticryptococcal antibody and soluble capsular 
polysaccharide (Aguirre and Miller 2002). Additionally, other cytokines have been shown to affect the infectious process of $C$. neoformans. Kleinschek et al. demonstrated that $C$. neoformans foci in the brains of wild-type mice were surrounded by abundant MHC class IIpositive microglia/macrophages, whereas in IL-23p19 knockout mice, macrophages were significantly less numerous and activation of microglial cells was markedly reduced (Kleinschek et al. 2006). Microglia from IL-23p19 knockout mice had also demonstrated impairment in the expression of MHC class II as well as IL-1 $\beta$, IL-6, and MCP-1 in the brain (Kleinschek et al. 2006).

It has recently been demonstrated that immunotherapy with anti-CD40 and IL-2 can protect mice against disseminated C. neoformans (Zhou et al. 2007). This protective effect was associated with microglial activation as reflected by the increase in MHC class II expression on brain CD45 ${ }^{\text {low }} \mathrm{CD} 11 \mathrm{~b}^{+}$cells (Zhou et al. 2007). Furthermore, experiments with IFN- $\gamma$ knockout mice and IFN- $\gamma \mathrm{R}$ knockout mice demonstrated that IFN- $\gamma$ was vital for microglial activation as well as anticryptococcal efficacy stimulated by anti-CD40/IL-2 treatment (Zhou et al. 2007). Interestingly, $\mathrm{CD}^{+} \mathrm{T}$ cells were not required for either microglial activation or anticryptococcal efficacy during anti-CD40/IL-2 treatment (Zhou et al. 2007).

Severe stress has also been shown to exacerbate many infections including $C$. neoformans (Shimoda et al. 2006). Shimoda et al. showed that restraint-stressed (RST) mice were more susceptible to intracerebral growth of $C$. neoformans than normal mice or food-and-waterdeprived (FWD) mice (Shimoda et al. 2006). It was demonstrated that after inoculation with microglia from the brains of RST mice, FWD mice susceptibility to cerebral cryptococcosis increased to the level observed in RST mice (Shimoda et al. 2006). In contrast, the adoptive transfer of microglia from normal or FWD mice had no effect on $C$. neoformans infections, which may be explained by the finding that microglia from RST mice produce CCL2/MCP-1, whereas microglia from FWD mice do not (Shimoda et al. 2006). These results indicate that resistance to C. neoformans is diminished in RST mice due to CCL2 production by microglia induced by restraint stress.

Certain chemicals have been shown to alter anticryptococcal activity such as morphine or chloroquine (Lipovsky et al. 1998; Sowa et al. 1997). Morphine enhances uptake of cryptococci in human microglia via $v$-opioid and complement receptors while suppressing phagocytosis of porcine microglia (Sowa et al. 1997). The reason(s) responsible for these differential effects are currently not understood. Chloroquine enhances the anticryptococcal activity of the murine microglia-derived cell line BV2 in vitro (Lipovsky et al. 1998).

\section{Histoplasma capsulatum}

Inhalation of $H$. capsulatum, a pathogenic fungus, may result in histoplasmosis, a significant emerging infectious disease that occurs mainly in immunocompromised individuals and transplant patients which is capable of disseminating to the brain (Saccente 2008). However, little is known about the immunobiology of Histoplasma infection in the CNS. Aravalli et al. recently demonstrated that TLR2 recognizes the $H$. capsulatum cell wall protein Yps3p and induces the activation of NF- $\kappa \mathrm{B}$ in primary microglial cells (Aravalli et al. 2008). These results showed that $H$. capsulatum Yps3p induced TLR2 signaling in wild-type microglia, but not in microglia isolated from TLR2 KO mice, confirming that Yps3p is a ligand for TLR2, the first demonstration of a fungal protein serving as a TLR ligand and mediating signaling in primary brain cells (Aravalli et al. 2008).

\section{Concluding remarks and outstanding questions}

Despite recent studies describing microglial responsiveness to several pathogens capable of CNS colonization, several issues remain relatively underexplored. In particular, a clear trend 
toward differential PRR usage by microglia to tailor inflammatory mediator secretion profiles to distinct CNS pathogens has not yet been identified. An understanding of how microglia may utilize PRRs to discriminate between divergent CNS pathogens could lead to the development of novel therapies for manipulating microglial responsiveness for the treatment of infectious disorders that have unwanted side effects. With regard to microglial recognition of infectious pathogens, it is probable that multiple PRRs are engaged to elicit maximal responses. For example, an intact bacterium likely engages one/more phagocytic receptors in addition to stimulation of one/multiple TLRs. Both pathways result in distinct effector functions, although cross-talk between phagocytic and inflammatory mediator secretion pathways exist (Mukhopadhyay et al. 2004; Underhill and Gantner 2004). The identity of such receptor repertoires and how they cooperate to maximize bacterial recognition by microglia remains to be defined.

Another issue that remains to be completely understood is what factors dictate whether microglia exert beneficial versus detrimental effects during the course of CNS infections? Likely, this regulation is complex and multifactorial being influenced by such parameters as infectious dose, duration of infection, whether the pathogen is contained focally within the CNS parenchyma or is distributed diffusely, as well as the nature of the inciting pathogen. In experimental models of bacterial meningitis, microglia have been suggested to have both beneficial and adverse effects. The former is represented by the potent pro-inflammatory response that ensues following exposure to meningitis-eliciting pathogens. It is envisioned that these mediators are, in part, responsible for the recruitment of professional phagocytes that function to limit bacterial replication. However, excessive microglial activation has been implicated in neuronal toxicity and apoptotic cell death, a major confound that accompanies bacterial meningitis. Another layer of complexity is revealed by the fact that pneumococci have been reported to induce microglial apoptosis, which may represent a mechanism to resolve inflammation. A similar dual role for microglia has been proposed during brain abscess formation induced by $S$. aureus. It is evident that CNS resident cells (i.e., microglia) are essential for the genesis of a protective innate immune response to infection; however, evidence also suggests that this inflammatory response persists beyond the point where no infectious bacteria can be demonstrated. In this scenario, we propose that residual PAMPs released from dead bacteria serve as a continual trigger for PRRs to sustain the inflammatory milieu. In essence, the CNS senses an active infection through the continued engagement of PRRs by bacterial debris; however, viable organisms no longer remain. Therefore, strategies to thwart inappropriate microglial activation at a point where inflammation is no longer beneficial could lead to less damage to surrounding normal parenchyma as a result of bystander destruction.

Another intriguing concept to consider is the potential for endogenous molecules (or so-called danger signals) to exacerbate microglial responses to bacteria. This point is especially relevant when one considers that a number of CNS infections are associated with some degree of necrotic cell damage, which releases endogenous molecules that are not typically accessible to the immune system. It remains to be determined whether infectious insults such as brain abscesses that are typified by extensive parenchymal necrosis are exacerbated by host molecules. This possibility will prove challenging to demonstrate experimentally due to issues as to how one can separate microglial responses to bacterial versus endogenous molecules in an in vivo setting.

In summary, although we have a good foundation for documenting microglial responsiveness to a cohort of CNS relevant pathogens, much work remains to be done. In particular, relatively little is known regarding microglial recognition of CNS fungal pathogens and parasitic infections (i.e., cerebral malaria). These issues are of particular importance due to the prevalence of these opportunistic infections in immunocompromised individuals such as AIDS or transplant patients. 


\section{Acknowledgments}

This work was supported by the NIH National Institute of Neurological Disorders and Stroke (NINDS; RO1s NS040740, NS055385, and NS053487) to T.K.

\section{References}

Adachi O, Kawai T, Takeda K, Matsumoto M, Tsutsui H, Sakagami M, Nakanishi K, Akira S. Targeted disruption of the MyD88 gene results in loss of IL-1- and IL-18-mediated function. Immunity 1998;9 (1):143-150. [PubMed: 9697844]

Aguirre K, Miller S. MHC class II-positive perivascular microglial cells mediate resistance to Cryptococcus neoformans brain infection. Glia 2002;39(2):184-188. [PubMed: 12112369]

Akira S. TLR signaling. Curr Top Microbiol Immunol 2006;311:1-16. [PubMed: 17048703]

Aloisi F. Immune function of microglia. Glia 2001;36(2):165-179. [PubMed: 11596125]

Aravalli RN, Hu S, Woods JP, Lokensgard JR. Histoplasma capsulatum yeast phase-specific protein Yps3p induces Toll-like receptor 2 signaling. J Neuroinflammation 2008;5:30. [PubMed: 18606009]

Baldwin AC, Kielian T. Persistent immune activation associated with a mouse model of Staphylococcus aureus-induced experimental brain abscess. J Neuroimmunol 2004;151(1-2):24-32. [PubMed: 15145600]

Bernardino AL, Myers TA, Alvarez X, Hasegawa A, Philipp MT. Toll-like receptors: insights into their possible role in the pathogenesis of lyme neuroborreliosis. Infect Immun 2008;76(10):4385-4395. [PubMed: 18694963]

Bernardino AL, Kaushal D, Philipp MT. The antibiotics doxycycline and minocycline inhibit the inflammatory responses to the lyme disease spirochete Borrelia burgdorferi. J Infect Dis 2009;199(9): 1379-1388. [PubMed: 19301981]

Blasi E, Barluzzi R, Mazzolla R, Tancini B, Saleppico S, Puliti M, Pitzurra L, Bistoni F. Role of nitric oxide and melanogenesis in the accomplishment of anticryptococcal activity by the BV-2 microglial cell line. J Neuroimmunol 1995;58(1):111-116. [PubMed: 7730446]

Brandenburg LO, Varoga D, Nicolaeva N, Leib SL, Wilms H, Podschun R, Wruck CJ, Schroder JM, Pufe T, Lucius R. Role of glial cells in the functional expression of LL-37/rat cathelin-related antimicrobial peptide in meningitis. J Neuropathol Exp Neurol 2008;67(11):1041-1054. [PubMed: 18957897]

Braun JS, Novak R, Murray PJ, Eischen CM, Susin SA, Kroemer G, Halle A, Weber JR, Tuomanen EI, Cleveland JL. Apoptosis-inducing factor mediates microglial and neuronal apoptosis caused by pneumococcus. J Infect Dis 2001;184(10):1300-1309. [PubMed: 11679919]

Braun JS, Sublett JE, Freyer D, Mitchell TJ, Cleveland JL, Tuomanen EI, Weber JR. Pneumococcal pneumolysin and $\mathrm{H}(2) \mathrm{O}(2)$ mediate brain cell apoptosis during meningitis. J Clin Invest 2002;109 (1):19-27. [PubMed: 11781347]

Burns K, Martinon F, Esslinger C, Pahl H, Schneider P, Bodmer JL, Di Marco F, French L, Tschopp J. MyD88, an adapter protein involved in interleukin-1 signaling. J Biol Chem 1998;273(20):1220312209. [PubMed: 9575168]

Carson MJ, Reilly CR, Sutcliffe JG, Lo D. Mature microglia resemble immature antigen-presenting cells. Glia 1998;22(1):72-85. [PubMed: 9436789]

Cassiani-Ingoni R, Cabral ES, Lunemann JD, Garza Z, Magnus T, Gelderblom H, Munson PJ, Marques A, Martin R. Borrelia burgdorferi induces TLR1 and TLR2 in human microglia and peripheral blood monocytes but differentially regulates HLA-class II expression. J Neuropathol Exp Neurol 2006;65 (6):540-548. [PubMed: 16783164]

Chao CC, Anderson WR, Hu S, Gekker G, Martella A, Peterson PK. Activated microglia inhibit multiplication of Toxoplasma gondii via a nitric oxide mechanism. Clin Immunol Immunopathol 1993;67(2):178-183. [PubMed: 8519093]

Chao CC, Gekker G, Hu S, Peterson PK. Human microglial cell defense against Toxoplasma gondii. The role of cytokines. J Immunol 1994;152(3):1246-1252. [PubMed: 8301129] 
Coban C, Ishii KJ, Uematsu S, Arisue N, Sato S, Yamamoto M, Kawai T, Takeuchi O, Hisaeda H, Horii T, et al. Pathological role of Toll-like receptor signaling in cerebral malaria. Int Immunol 2007;19 (1):67-79. [PubMed: 17135446]

Colton C, Wilt S, Gilbert D, Chernyshev O, Snell J, Dubois-Dalcq M. Species differences in the generation of reactive oxygen species by microglia. Mol Chem Neuropathol 1996;28(1-3):15-20. [PubMed: 8871937]

Das Sarma J, Ciric B, Marek R, Sadhukhan S, Caruso ML, Shafagh J, Fitzgerald DC, Shindler KS, Rostami AM. Functional interleukin-17 receptor A is expressed in central nervous system glia and upregulated in experimental autoimmune encephalomyelitis. J Neuroinflammation 2009;6(1):14. [PubMed: 19400960]

Deckert M, Sedgwick JD, Fischer E, Schluter D. Regulation of microglial cell responses in murine Toxoplasma encephalitis by CD200/CD200 receptor interaction. Acta Neuropathol 2006;111(6): 548-558. [PubMed: 16718351]

Deckert-Schluter M, Buck C, Weiner D, Kaefer N, Rang A, Hof H, Wiestler OD, Schluter D. Interleukin-10 downregulates the intracerebral immune response in chronic Toxoplasma encephalitis. J Neuroimmunol 1997;76(1-2):167-176. [PubMed: 9184647]

Deininger MH, Kremsner PG, Meyermann R, Schluesener H. Macrophages/microglial cells in patients with cerebral malaria. Eur Cytokine Netw 2002;13(2):173-185. [PubMed: 12101073]

Djukic M, Mildner A, Schmidt H, Czesnik D, Bruck W, Priller J, Nau R, Prinz M. Circulating monocytes engraft in the brain, differentiate into microglia and contribute to the pathology following meningitis in mice. Brain 2006;129(Pt 9):2394-2403. [PubMed: 16891321]

Dobbie M, Crawley J, Waruiru C, Marsh K, Surtees R. Cerebrospinal fluid studies in children with cerebral malaria: an excitotoxic mechanism? Am J Trop Med Hyg 2000;62(2):284-290. [PubMed: 10813486]

Engwerda C, Belnoue E, Gruner AC, Renia L. Experimental models of cerebral malaria. Curr Top Microbiol Immunol 2005;297:103-143. [PubMed: 16265904]

Esen N, Kielian T. Central role for MyD88 in the responses of microglia to pathogen-associated molecular patterns. J Immunol 2006;176(11):6802-6811. [PubMed: 16709840]

Esen N, Kielian T. Effects of low dose GM-CSF on microglial inflammatory profiles to diverse pathogenassociated molecular patterns (PAMPs). J Neuroinflammation 2007;4:10. [PubMed: 17374157]

Fischer HG, Reichmann G. Brain dendritic cells and macrophages/microglia in central nervous system inflammation. J Immunol 2001;166(4):2717-2726. [PubMed: 11160337]

Fischer HG, Bielinsky AK, Nitzgen B, Daubener W, Hadding U. Functional dichotomy of mouse microglia developed in vitro: differential effects of macrophage and granulocyte/macrophage colonystimulating factor on cytokine secretion and antitoxoplasmic activity. J Neuroimmunol 1993;45(12):193-201. [PubMed: 8331161]

Fischer HG, Nitzgen B, Reichmann G, Gross U, Hadding U. Host cells of Toxoplasma gondii encystation in infected primary culture from mouse brain. Parasitol Res 1997;83(7):637-641. [PubMed: 9272550]

Ford AL, Goodsall AL, Hickey WF, Sedgwick JD. Normal adult ramified microglia separated from other central nervous system macrophages by flow cytometric sorting. Phenotypic differences defined and direct ex vivo antigen presentation to myelin basic protein-reactive CD4+ T cells compared. J Immunol 1995;154(9):4309-4321. [PubMed: 7722289]

Freund YR, Zaveri NT, Javitz HS. In vitro investigation of host resistance to Toxoplasma gondii infection in microglia of BALB/c and CBA/Ca mice. Infect Immun 2001;69(2):765-772. [PubMed: 11159966]

Galiza EP, Heath PT. Improving the outcome of neonatal meningitis. Curr Opin Infect Dis 2009;22(3): 229-234. [PubMed: 19333122]

Garcao P, Oliveira CR, Agostinho P. Comparative study of microglia activation induced by amyloid-beta and prion peptides: role in neurodegeneration. J Neurosci Res 2006;84(1):182-193. [PubMed: 16634056]

Garg S, Nichols JR, Esen N, Liu S, Phulwani NK, Syed MMd, Wood WH, Zhang Y, Becker KG, Aldrich A, Kielian T. MyD88 expression by CNS-resident cells is pivotal for eliciting protective immunity in brain abscesses. ASN Neuro. 2009 doi:10.1042/AN20090004. 
Goos M, Lange P, Hanisch UK, Prinz M, Scheffel J, Bergmann R, Ebert S, Nau R. Fibronectin is elevated in the cerebrospinal fluid of patients suffering from bacterial meningitis and enhances inflammation caused by bacterial products in primary mouse microglial cell cultures. J Neurochem 2007;102(6): 2049-2060. [PubMed: 17561936]

Griffith JW, O'Connor C, Bernard K, Town T, Goldstein DR, Bucala R. Toll-like receptor modulation of murine cerebral malaria is dependent on the genetic background of the host. J Infect Dis 2007;196 (10):1553-1564. [PubMed: 18008236]

Gurley C, Nichols J, Liu S, Phulwani NK, Esen N, Kielian T. Microglia and astrocyte activation by Tolllike receptor ligands: modulation by PPAR-gamma agonists. PPAR Res 2008;2008:453120. [PubMed: 18584038]

Hanisch UK. Microglia as a source and target of cytokines. Glia 2002;40(2):140-155. [PubMed: 12379902]

Hanisch UK, Prinz M, Angstwurm K, Hausler KG, Kann O, Kettenmann H, Weber JR. The protein tyrosine kinase inhibitor AG126 prevents the massive microglial cytokine induction by pneumococcal cell walls. Eur J Immunol 2001;31(7):2104-2115. [PubMed: 11449364]

Hengge UR, Tannapfel A, Tyring SK, Erbel R, Arendt G, Ruzicka T. Lyme borreliosis. Lancet Infect Dis 2003;3(8):489-500. [PubMed: 12901891]

Hill JO, Aguirre KM. CD4+ T cell-dependent acquired state of immunity that protects the brain against Cryptococcus neoformans. J Immunol 1994;152(5):2344-2350. [PubMed: 7907637]

Hunt NH, Golenser J, Chan-Ling T, Parekh S, Rae C, Potter S, Medana IM, Miu J, Ball HJ. Immunopathogenesis of cerebral malaria. Int J Parasitol 2006;36(5):569-582. [PubMed: 16678181]

Husemann J, Loike JD, Anankov R, Febbraio M, Silverstein SC. Scavenger receptors in neurobiology and neuropathology: their role on microglia and other cells of the nervous system. Glia 2002;40(2): 195-205. [PubMed: 12379907]

Idro R, Jenkins NE, Newton CR. Pathogenesis, clinical features, and neurological outcome of cerebral malaria. Lancet Neurol 2005;4(12):827-840. [PubMed: 16297841]

Ishigame H, Kakuta S, Nagai T, Kadoki M, Nambu A, Komiyama Y, Fujikado N, Tanahashi Y, Akitsu A, Kotaki H, et al. Differential roles of interleukin-17A and $-17 \mathrm{~F}$ in host defense against mucoepithelial bacterial infection and allergic responses. Immunity 2009;30(1):108-119. [PubMed: 19144317]

Jones ME, Draghi DC, Karlowsky JA, Sahm DF, Bradley JS. Prevalence of antimicrobial resistance in bacteria isolated from central nervous system specimens as reported by U.S. hospital laboratories from 2000 to 2002. Ann Clin Microbiol Antimicrob 2004;3:3. [PubMed: 15043754]

Kawanokuchi J, Shimizu K, Nitta A, Yamada K, Mizuno T, Takeuchi H, Suzumura A. Production and functions of IL-17 in microglia. J Neuroimmunol 2008;194(1-2):54-61. [PubMed: 18164424]

Kielian T. Immunopathogenesis of brain abscess. J Neuroinflammation 2004;1(1):16. [PubMed: 15315708]

Kielian T. Toll-like receptors in central nervous system glial inflammation and homeostasis. J Neurosci Res 2006;83(5):711-730. [PubMed: 16541438]

Kielian T, Barry B, Hickey WF. CXC chemokine receptor-2 ligands are required for neutrophil-mediated host defense in experimental brain abscesses. J Immunol 2001;166(7):4634-4643. [PubMed: 11254722]

Kielian T, Mayes P, Kielian M. Characterization of microglial responses to Staphylococcus aureus: effects on cytokine, costimulatory molecule, and Toll-like receptor expression. J Neuroimmunol 2002;130(1-2):86-99. [PubMed: 12225891]

Kielian T, Bearden ED, Baldwin AC, Esen N. IL-1 and TNF-alpha play a pivotal role in the host immune response in a mouse model of Staphylococcus aureus-induced experimental brain abscess. J Neuropathol Exp Neurol 2004;63(4):381-396. [PubMed: 15099027]

Kielian T, Esen N, Bearden ED. Toll-like receptor 2 (TLR2) is pivotal for recognition of S. aureus peptidoglycan but not intact bacteria by microglia. Glia 2005;49(4):567-576. [PubMed: 15593098]

Kielian T, Phulwani NK, Esen N, Syed MM, Haney AC, McCastlain K, Johnson J. MyD88-dependent signals are essential for the host immune response in experimental brain abscess. J Immunol 2007;178 (7):4528-4537. [PubMed: 17372011] 
Kim YS, Tauber MG. Neurotoxicity of glia activated by gram-positive bacterial products depends on nitric oxide production. Infect Immun 1996;64(8):3148-3153. [PubMed: 8757846]

Kim K, Weiss LM. Toxoplasma: the next 100 years. Microbes Infect 2008;10(9):978-984. [PubMed: 18672085]

Kleinert H, Pautz A, Linker K, Schwarz PM. Regulation of the expression of inducible nitric oxide synthase. Eur J Pharmacol 2004;500(1-3):255-266. [PubMed: 15464038]

Kleinschek MA, Muller U, Brodie SJ, Stenzel W, Kohler G, Blumenschein WM, Straubinger RK, McClanahan T, Kastelein RA, Alber G. IL-23 enhances the inflammatory cell response in Cryptococcus neoformans infection and induces a cytokine pattern distinct from IL-12. J Immunol 2006;176(2):1098-1106. [PubMed: 16393998]

Koedel U, Scheld WM, Pfister HW. Pathogenesis and pathophysiology of pneumococcal meningitis. Lancet Infect Dis 2002;2(12):721-736. [PubMed: 12467688]

Larsen PH, Holm TH, Owens T. Toll-like receptors in brain development and homeostasis. Sci STKE 2007;2007(402):pe47. [PubMed: 17785714]

Lee SC, Kress Y, Dickson DW, Casadevall A. Human microglia mediate anti-Cryptococcus neoformans activity in the presence of specific antibody. J Neuroimmunol 1995;62(1):43-52. [PubMed: 7499491]

Lehnardt S, Wennekamp J, Freyer D, Liedtke C, Krueger C, Nitsch R, Bechmann I, Weber JR, Henneke P. TLR2 and caspase- 8 are essential for group B Streptococcus-induced apoptosis in microglia. J Immunol 2007;179(9):6134-6143. [PubMed: 17947688]

Lepenies B, Cramer JP, Burchard GD, Wagner H, Kirschning CJ, Jacobs T. Induction of experimental cerebral malaria is independent of TLR2/4/9. Med Microbiol Immunol 2008;197(1):39-44. [PubMed: 17668237]

Lipovsky MM, Gekker G, Anderson WR, Molitor TW, Peterson PK, Hoepelman AI. Phagocytosis of nonopsonized Cryptococcus neoformans by swine microglia involves CD14 receptors. Clin Immunol Immunopathol 1997;84(2):208-211. [PubMed: 9245554]

Lipovsky MM, Juliana AE, Gekker G, Hu S, Hoepelman AI, Peterson PK. Effect of cytokines on anticryptococcal activity of human microglial cells. Clin Diagn Lab Immunol 1998;5(3):410-411. [PubMed: 9606001]

Lu CH, Chang WN, Lui CC. Strategies for the management of bacterial brain abscess. J Clin Neurosci 2006;13(10):979-985. [PubMed: 17056261]

Luder CG, Giraldo-Velasquez M, Sendtner M, Gross U. Toxoplasma gondii in primary rat CNS cells: differential contribution of neurons, astrocytes, and microglial cells for the intracerebral development and stage differentiation. Exp Parasitol 1999;93(1):23-32. [PubMed: 10464035]

Luder CG, Lang C, Giraldo-Velasquez M, Algner M, Gerdes J, Gross U. Toxoplasma gondii inhibits MHC class II expression in neural antigen-presenting cells by down-regulating the class II transactivator CIITA. J Neuroimmunol 2003;134(1-2):12-24. [PubMed: 12507768]

Manning SD. Molecular epidemiology of Streptococcus agalactiae (group B Streptococcus). Front Biosci 2003;8:s1-s18. [PubMed: 12456367]

Mathisen GE, Johnson JP. Brain abscess. Clin Infect Dis 1997;25(4):763-779. quiz 780-1. [PubMed: 9356788]

Mausberg AK, Jander S, Reichmann G. Intracerebral granulocyte-macrophage colony-stimulating factor induces functionally competent dendritic cells in the mouse brain. Glia 2009;57:1341-1350. [PubMed: 19229994]

McGilvray ID, Serghides L, Kapus A, Rotstein OD, Kain KC. Nonopsonic monocyte/macrophage phagocytosis of Plasmodium falciparum-parasitized erythrocytes: a role for CD36 in malarial clearance. Blood 2000;96(9):3231-3240. [PubMed: 11050008]

McKimmie CS, Roy D, Forster T, Fazakerley JK. Innate immune response gene expression profiles of N9 microglia are pathogen-type specific. J Neuroimmunol 2006;175(1-2):128-141. [PubMed: 16697053]

Medana IM, Hunt NH, Chan-Ling T. Early activation of microglia in the pathogenesis of fatal murine cerebral malaria. Glia 1997;19(2):91-103. [PubMed: 9034826]

Medana IM, Chan-Ling T, Hunt NH. Reactive changes of retinal microglia during fatal murine cerebral malaria: effects of dexamethasone and experimental permeabilization of the blood-brain barrier. Am J Pathol 2000;156(3):1055-1065. [PubMed: 10702421] 
Miklossy J, Kasas S, Zurn AD, McCall S, Yu S, McGeer PL. Persisting atypical and cystic forms of Borrelia burgdorferi and local inflammation in Lyme neuroborreliosis. J Neuroinflammation 2008;5:40. [PubMed: 18817547]

Montoya JG, Liesenfeld O. Toxoplasmosis. Lancet 2004;363(9425):1965-1976. [PubMed: 15194258]

Mukhopadhyay S, Herre J, Brown GD, Gordon S. The potential for Toll-like receptors to collaborate with other innate immune receptors. Immunology 2004;112(4):521-530. [PubMed: 15270722]

Murray HW, Rubin BY, Masur H, Roberts RB. Impaired production of lymphokines and immune (gamma) interferon in the acquired immunodeficiency syndrome. N Engl J Med 1984;310(14):883889. [PubMed: 6422299]

Nau R, Bruck W. Neuronal injury in bacterial meningitis: mechanisms and implications for therapy. Trends Neurosci 2002;25(1):38-45. [PubMed: 11801337]

Nichols JR, Aldrich AL, Mariani MM, Vidlak D, Esen N, Kielian T. TLR2 deficiency leads to increased Th17 infiltrates in experimental brain abscesses. J Immunol 2009;182(11):7119-7130. [PubMed: 19454709]

O'Neill LA, Bowie AG. The family of five: TIR-domain-containing adaptors in Toll-like receptor signalling. Nat Rev Immunol 2007;7(5):353-364. [PubMed: 17457343]

Pachner AR, Gelderblom H, Cadavid D. The rhesus model of Lyme neuroborreliosis. Immunol Rev 2001;183:186-204. [PubMed: 11782257]

Pashenkov M, Teleshova N, Kouwenhoven M, Smirnova T, Jin YP, Kostulas V, Huang YM, Pinegin B, Boiko A, Link H. Recruitment of dendritic cells to the cerebrospinal fluid in bacterial neuroinfections. J Neuroimmunol 2002;122(1-2):106-116. [PubMed: 11777549]

Patel SN, Serghides L, Smith TG, Febbraio M, Silverstein RL, Kurtz TW, Pravenec M, Kain KC. CD36 mediates the phagocytosis of Plasmodium falciparum-infected erythrocytes by rodent macrophages. J Infect Dis 2004;189(2):204-213. [PubMed: 14722884]

Peppoloni S, Colombari B, Neglia R, Quaglino D, Iannelli F, Oggioni MR, Pozzi G, Blasi E. The lack of Pneumococcal surface protein C (PspC) increases the susceptibility of Streptococcus pneumoniae to the killing by microglia. Med Microbiol Immunol 2006;195(1):21-28. [PubMed: 15909201]

Peterson PK, Hu S, Anderson WR, Chao CC. Nitric oxide production and neurotoxicity mediated by activated microglia from human versus mouse brain. J Infect Dis 1994;170(2):457-460. [PubMed: 8035037]

Pfister HW, Rupprecht TA. Clinical aspects of neuroborreliosis and post-Lyme disease syndrome in adult patients. Int J Med Microbiol 2006;296(Suppl 40):11-16. [PubMed: 16524775]

Pfister HW, Feiden W, Einhaupl KM. Spectrum of complications during bacterial meningitis in adults. Results of a prospective clinical study. Arch Neurol 1993;50(6):575-581. [PubMed: 8503793]

Pfister HW, Wilske B, Weber K. Lyme borreliosis: basic science and clinical aspects. Lancet 1994;343 (8904):1013-1016. [PubMed: 7909052]

Ponomarev ED, Novikova M, Maresz K, Shriver LP, Dittel BN. Development of a culture system that supports adult microglial cell proliferation and maintenance in the resting state. J Immunol Methods 2005;300(1-2):32-46. [PubMed: 15893321]

Prasad KN, Mishra AM, Gupta D, Husain N, Husain M, Gupta RK. Analysis of microbial etiology and mortality in patients with brain abscess. J Infect 2006;53(4):221-227. [PubMed: 16436297]

Prinz M, Kann O, Draheim HJ, Schumann RR, Kettenmann H, Weber JR, Hanisch UK. Microglial activation by components of gram-positive and -negative bacteria: distinct and common routes to the induction of ion channels and cytokines. J Neuropathol Exp Neurol 1999;58(10):1078-1089. [PubMed: 10515231]

Ramesh G, Borda JT, Dufour J, Kaushal D, Ramamoorthy R, Lackner AA, Philipp MT. Interaction of the Lyme disease spirochete Borrelia burgdorferi with brain parenchyma elicits inflammatory mediators from glial cells as well as glial and neuronal apoptosis. Am J Pathol 2008;173(5):14151427. [PubMed: 18832582]

Rasley A, Anguita J, Marriott I. Borrelia burgdorferi induces inflammatory mediator production by murine microglia. J Neuroimmunol 2002;130(1-2):22-31. [PubMed: 12225885]

Rasley A, Tranguch SL, Rati DM, Marriott I. Murine glia express the immunosuppressive cytokine, interleukin-10, following exposure to Borrelia burgdorferi or Neisseria meningitidis. Glia 2006;53 (6):583-592. [PubMed: 16419089] 
Rock RB, Gekker G, Hu S, Sheng WS, Cheeran M, Lokensgard JR, Peterson PK. Role of microglia in central nervous system infections. Clin Microbiol Rev 2004;17(4):942-964. table of contents. [PubMed: 15489356]

Rozenfeld C, Martinez R, Figueiredo RT, Bozza MT, Lima FR, Pires AL, Silva PM, Bonomo A, LannesVieira J, De Souza W, et al. Soluble factors released by Toxoplasma gondii-infected astrocytes down-modulate nitric oxide production by gamma interferon-activated microglia and prevent neuronal degeneration. Infect Immun 2003;71(4):2047-2057. [PubMed: 12654825]

Rupprecht TA, Koedel U, Fingerle V, Pfister HW. The pathogenesis of lyme neuroborreliosis: from infection to inflammation. Mol Med 2008;14(3-4):205-212. [PubMed: 18097481]

Saccente M. Central nervous system histoplasmosis. Curr Treat Options Neurol 2008;10(3):161-167. [PubMed: 18579019]

Scheld WM, Koedel U, Nathan B, Pfister HW. Pathophysiology of bacterial meningitis: mechanism(s) of neuronal injury. J Infect Dis 2002;186(Suppl 2):S225-S233. [PubMed: 12424702]

Schluesener HJ, Kremsner PG, Meyermann R. Widespread expression of MRP8 and MRP14 in human cerebral malaria by microglial cells. Acta Neuropathol 1998;96(6):575-580. [PubMed: 9845287]

Schluter D, Hein A, Dorries R, Deckert-Schluter M. Different subsets of T cells in conjunction with natural killer cells, macrophages, and activated microglia participate in the intracerebral immune response to Toxoplasma gondii in athymic nude and immunocompetent rats. Am J Pathol 1995;146 (4):999-1007. [PubMed: 7717465]

Schluter D, Kaefer N, Hof H, Wiestler OD, Deckert-Schluter M. Expression pattern and cellular origin of cytokines in the normal and Toxoplasma gondii-infected murine brain. Am J Pathol 1997;150 (3):1021-1035. [PubMed: 9060839]

Schluter D, Kwok LY, Lutjen S, Soltek S, Hoffmann S, Korner H, Deckert M. Both lymphotoxin-alpha and TNF are crucial for control of Toxoplasma gondii in the central nervous system. J Immunol 2003;170(12):6172-6182. [PubMed: 12794148]

Schneemann M, Schoedon G, Hofer S, Blau N, Guerrero L, Schaffner A. Nitric oxide synthase is not a constituent of the antimicrobial armature of human mononuclear phagocytes. J Infect Dis 1993;167 (6):1358-1363. [PubMed: 7684756]

Schofield L, Grau GE. Immunological processes in malaria pathogenesis. Nat Rev Immunol 2005;5(9): 722-735. [PubMed: 16138104]

Sedgwick JD, Schwender S, Imrich H, Dorries R, Butcher GW, ter Meulen V. Isolation and direct characterization of resident microglial cells from the normal and inflamed central nervous system. Proc Natl Acad Sci USA 1991;88(16):7438-7442. [PubMed: 1651506]

Shimoda M, Jones VC, Kobayashi M, Suzuki F. Microglial cells from psychologically stressed mice as an accelerator of cerebral cryptococcosis. Immunol Cell Biol 2006;84(6):551-556. [PubMed: 16956390]

Somand D, Meurer W. Central nervous system infections. Emerg Med Clin North Am 2009;27(1):89100. ix. [PubMed: 19218021]

Sowa G, Gekker G, Lipovsky MM, Hu S, Chao CC, Molitor TW, Peterson PK. Inhibition of swine microglial cell phagocytosis of Cryptococcus neoformans by femtomolar concentrations of morphine. Biochem Pharmacol 1997;53(6):823-828. [PubMed: 9113103]

Strack A, Schluter D, Asensio VC, Campbell IL, Deckert M. Regulation of the kinetics of intracerebral chemokine gene expression in murine Toxoplasma encephalitis: impact of host genetic factors. Glia 2002;40(3):372-377. [PubMed: 12420316]

Szklarczyk A, Stins M, Milward EA, Ryu H, Fitzsimmons C, Sullivan D, Conant K. Glial activation and matrix metalloproteinase release in cerebral malaria. J Neurovirol 2007;13(1):2-10. [PubMed: 17454443]

Tambuyzer BR, Ponsaerts P, Nouwen EJ. Microglia: gatekeepers of central nervous system immunology. J Leukoc Biol 2009;85(3):352-370. [PubMed: 19028958]

Togbe D, Schofield L, Grau GE, Schnyder B, Boissay V, Charron S, Rose S, Beutler B, Quesniaux VF, Ryffel B. Murine cerebral malaria development is independent of toll-like receptor signaling. Am J Pathol 2007;170(5):1640-1648. [PubMed: 17456769]

Townsend GC, Scheld WM. Infections of the central nervous system. Adv Intern Med 1998;43:403-447. [PubMed: 9506189] 
Toy D, Kugler D, Wolfson M, Vanden Bos T, Gurgel J, Derry J, Tocker J, Peschon J. Cutting edge: interleukin 17 signals through a heteromeric receptor complex. J Immunol 2006;177(1):36-39. [PubMed: 16785495]

Trajkovic V, Stosic-Grujicic S, Samardzic T, Markovic M, Miljkovic D, Ramic Z, Mostarica Stojkovic M. Interleukin-17 stimulates inducible nitric oxide synthase activation in rodent astrocytes. J Neuroimmunol 2001;119(2):183-191. [PubMed: 11585620]

Underhill DM, Gantner B. Integration of Toll-like receptor and phagocytic signaling for tailored immunity. Microbes Infect 2004;6(15):1368-1373. [PubMed: 15596122]

Wennekamp J, Henneke P. Induction and termination of inflammatory signaling in group B streptococcal sepsis. Immunol Rev 2008;225:114-127. [PubMed: 18837779]

Wesche H, Henzel WJ, Shillinglaw W, Li S, Cao Z. MyD88: an adapter that recruits IRAK to the IL-1 receptor complex. Immunity 1997;7(6):837-847. [PubMed: 9430229]

Zhou Q, Gault RA, Kozel TR, Murphy WJ. Protection from direct cerebral cryptococcus infection by interferon-gamma-dependent activation of microglial cells. J Immunol 2007;178(9):5753-5761. [PubMed: 17442959] 